\title{
Toxic oxygen metabolite production by circulating phagocytic cells in inflammatory bowel disease
}

\author{
J G Williams, L E Hughes, M B Hallett
}

\begin{abstract}
To investigate the possibility that the oxidative capacity of phagocytic cells may be defective in inflammatory bowel disease, toxic oxygen metabolite production by circulating neutrophils and monocytes has been measured by luminol dependent chemiluminescence. Neutrophils from patients with Crohn's disease and ulcerative colitis produced significantly lower chemiluminescent responses after chemotactic stimulation with formylmethionylleucylphenylalanine (fMLP) than neutrophils from control patients, $p=0.018$ and 0.043 respectively. Chemiluminescent responses of neutrophils from patients with inflammatory bowel disease, however, were similar to control responses when cells were stimulated with latex beads or phorbol myristate acetate. Monocytes from patients with Crohn's disease produced significantly greater levels of chemiluminescence than control monocytes when stimulated with either fMLP $(p<0.002)$, phorbol myristate acetate $(p<0.0005)$ or latex beads $(p<0.002)$. Monocytes from patients with ulcerative colitis also produced significantly greater levels of chemiluminescence than controls when stimulated with latex beads $(p<0.5)$ or phorbol myristate acetate $(p<0.0005)$, although there was no difference in the level of chemiluminescence in response to fMLP. These results exclude a generalised defect in phagocytic cell oxidase activity in inflammatory bowel disease and suggest that circulating monocytes are 'activated'.
\end{abstract}

The aetiology of Crohn's disease and ulcerative colitis remains uncertain. Phagocytic cells are prominent in the inflamed bowel wall in both conditions.' Since the work of Metchnikoff, ${ }^{2}$ neutrophils and macrophages have been implicated in the pathogenesis of tissue damage at inflammatory sites. These cells are able to generate highly reactive metabolites of oxygen such as hydrogen peroxide $\left(\mathrm{H}_{2} \mathrm{O}_{2}\right)$ and hypochlorite $\left(\mathrm{OCl}^{-}\right)$as well as the superoxide $\left(\mathrm{O}_{2}\right)$ and hydroxyl radicals $\left(\mathrm{OH}^{\circ}\right){ }^{34}$ Although these products of oxygen are involved in bacterial killing, their production outside the cell may also cause tissue damage. ${ }^{5}$

One feature of Crohn's disease is the typical non-caseating granuloma ${ }^{6}$ Parallels have been drawn between Crohn's disease and chronic granulomatous disease, where granulomas similar to those seen in Crohn's disease have been described in the rectum and the terminal ileum of symptomatic patients. ${ }^{7}$ The oxidative capacity of circulating phagocytic cells from patients with chronic granulomatous disease is defective, these cells being unable to produce toxic oxygen metabolites when stimulated. ${ }^{8}$ This has led to speculation that phagocyte function in inflammatory bowel disease is in some way defective. ${ }^{9}$

Neutrophils and macrophages migrating into the tissues originate from the circulating pool of neutrophils and monocytes. Therefore, any generalised defect in phagocytic function should be present in the circulating cells.

In this paper, the oxidative capacity of circulating neutrophils and monocytes has been assessed by a sensitive chemiluminescent technique to investigate the possibility that the oxidative capacity of these cells may be defective in inflammatory bowel disease.

\section{Methods}

PATIENTS

The diagnosis of Crohn's disease and ulcerative colitis was based on accepted clinical, radiological, endoscopic, and histological criteria. The severity of Crohn's disease was assessed by the criteria of DeDombal $e t a l^{10}$ and the severity of ulcerative colitis by the criteria of Truelove and Witts. " Both these systems identify patients with mild, moderate, and severe disease. Patients with moderate and severe disease were grouped together as having active disease and patients with mild disease as having inactive disease. Control subjects included healthy volunteers, and patients with other non-inflammatory gastrointestinal pathologies - for example, haemorrhoids, fissure in ano, colonic polyps, and gastrointestinal malignancies.

Neutrophil chemiluminescence and monocyte chemiluminescence was studied in different cohorts of patients with Crohn's disease and ulcerative colitis, as well as different control groups.

\section{NEUTROPHIL STUDIES}

In this study there were 25 control subjects (mean age 47 years, range $25-79$ ) and 33 patients with Crohn's disease (mean age 42 years, range 16-78), of which 10 were asymptomatic. Four of these were receiving no treatment, four were on prednisolone alone, one was on 5-amino-salicylic acid (5ASA) and prednisolone and a further patient was on 5ASA alone. Six patients had Crohn's disease confined to the small bowel and in the remaining four, only the colon was involved. Of the patients with active disease, six were not taking any medication, 11 were taking prednisolone alone, four were taking 5ASA in combination with prednisolone, and one patient
Address for correspondenc Mr J Graham Williams, University of Wales College of Medicine, Heath Park, Cardiff CF4 4XN, Wales.

Accepted for publication 18 April 1989
Department of Surgery, College of Medicine Heath Park Cardiff 
5ASA alone. Seventeen patients had only small bowel disease, four only colonic disease and the remaining two had both small and large bowel disease. Of the 19 patients with ulcerative colitis (mean age 45 years, range 21-72), five were asymptomatic, one of which was off treatment and two were on prednisolone and two were on salazopyrin. Of the patients with active disease, two were on prednisolone alone, and the remaining patients were taking prednisolone in combination with 5ASA.

\section{MONOCYTE STUDIES}

In this study there were 16 control subjects (mean age 50 years, range $22-81$ ) and 20 patients with Crohn's disease (mean age 46 years, range 27-76), of which five were asymptomatic, two of whom were off treatment, two on 5ASA and one on prednisolone. Four of these patients had Crohn's disease confined to the small bowel and in the fifth, both the small and large bowel were involved. The remaining patients had active disease, three of whom wee off treatment, eight were on prednisolone and two on 5ASA as sole therapy and a further two were on a combination of the two drugs. Four patients had Crohn's disease confined to the small bowel, in nine only the large bowel was involved and the remaining two patients had both large and small bowel involvement. There were 17 patients with ulcerative colitis (mean age 46 years, range 22 72). Six were asymptomatic, two of these were off treatment, one one prednisolone and one on sulphasalazine and two on a combination of the two drugs. Of the patients who had active disease, two were off treatment, and the remainder were on prednisolone and 5ASA or sulphasalazine.

\section{ISOLATION OF PHAGOCYTIC CELLS}

\section{Neutrophils}

Neutrophils were isolated from $20 \mathrm{ml}$ freshly drawn heparinised $(10 \mathrm{IU} / \mathrm{ml})$ whole blood, after dextran sedimentation of erythrocytes at $1 \mathrm{~g}$ for $45 \mathrm{~min}$ at room temperature. ${ }^{12}$ The leucocyte rich plasma was layered over an equal volume of Ficoll-paque (Pharmacia, Upsala, Sweden) and centrifuged at $200 \mathrm{~g}$ for 30 minutes. Erythrocytes, contaminating the neutrophil pellet, were destroyed by osmotic lysis with water. Neutrophils were washed twice in HEPES (N-2-Hydroxyethylpiperazine- $\mathrm{N}$-2-ethanesulphonic acid) buffered Krebs solution (HBK) containing 120 $\mathrm{mM} \mathrm{NaCl}, 4.8 \mathrm{mM} \mathrm{KCl}, 1.2 \mathrm{mM} \mathrm{Mg} \mathrm{SO}_{4}, 1 \cdot 2$ $\mathrm{mM} \mathrm{KH} \mathrm{KO}_{4} 1.3 \mathrm{mM} \mathrm{CaCl}, 0.1 \%$ bovine serum albumin and $25 \mathrm{mM}$ HEPES, $\mathrm{pH}$ adjusted to $7 \cdot 4$ with $\mathrm{NaOH}$. Cells were resuspended in fresh HBK $\left(1-6 \times 10^{6} / \mathrm{ml}\right)$ and stored on melting ice until required.

Purity was assessed in fixed preparations of the isolated cells $(>95 \%$.) Viability was assessed by the exclusion of trypan blue $0 \cdot 1 \%$ and $(>95 \%$.) drawn heparinised blood ( $10 \mathrm{IU} / \mathrm{ml})$, diluted $1: 1$ with HBK. Blood was gently layered over an equal volume of Ficoll/paque and centrifuged at $200 \mathrm{~g}$ for 30 minutes. Mononuclear cells were retrieved from the interface of the plasma and Ficoll, and washed twice in HBK before being stored on melting ice. Cytological preparations were made of each sample of mononuclear cells and stained with non-specific esterase to identify monocytes in each sample. ${ }^{13}$ The proportion of monocytes in each sample was calculated (7$50 \%$ ), and from this, the number of monocytes $/ \mathrm{ml}\left(0 \cdot 5-3 \times 10^{6}\right)$. Neutrophil contamination was $<5 \%$ and viability of mononuclear cells $>95 \%$.

\section{MEASUREMENT OF TOXIC OXYGEN}

\section{METABOLITE PRODUCTION}

Toxic oxygen metabolite production by both neutrophils and monocytes was measured by luminol dependent chemiluminescence) ${ }^{14}$ in purpose built apparatus). ${ }^{15}$ This consisted of a light-tight, thermostatically controlled specimen chamber, exposed to a photomultiplier tube (Thorn EMI $30 \mathrm{~mm}$, bialkaline front surface no. 9924B. High voltage supply $940 \mathrm{~V}$, discriminator $0 \cdot 1 \mathrm{~V})$. Quantitative readings of luminescence were made off a digital read-out and recorded continuously with a pen chart recorder.

One millilitre of cell suspension was placed in a plastic tube and luminol (Sigma Chemical Co, Poole, England), dissolved in DMSO, was added (final concentration luminol $11 \mu \mathrm{M} 0 \cdot 2 \%$ $\mathrm{v} / \mathrm{v}$ DMSO). The tube was incubated for five minutes at $37^{\circ} \mathrm{C}$ before being placed in the specimen chamber. The level of resting chemiluminescence was recorded before addition of the stimulus.

Three different stimuli were used: (1) $4 \beta$ phorbol-myristate-acetate (PMA) dissolved in DMSO (final concentration $1 \mu \mathrm{g} / \mathrm{ml}$ )

(2) The chemotactic peptide formyl-methionylleucyl-phenylalanine (fMLP) (Sigma, final concentraton $1 \mu \mathrm{M}$ ). (3) Latex beads (Polysciences inc. Northampton) $0.74 \mu \mathrm{m}$ diameter, $10^{9}$ beads $/ \mathrm{ml}$.

For each cell sample and stimulus, peak stimulated chemiluminescence was recorded. Triplicate measurements were made on separate aliquots of the cells studied. The basal level was subtracted from the peak level and the mean chemiluminescent response per $10^{6}$ cells calculated.

As the chemiluminescent responses of each group of patients were not normally distributed, median values were calculated and statistical comparisons between the three groups were made using the Mann Whitney U test.

The relationship between cell number and chemiluminescent response was assessed using the Pearson correlation coefficient, by measuring the chemiluminescent response of increasing concentrations of neutrophils $\left(1 \times 10^{6}-1 \cdot 2 \times 10^{7}\right)$ $\mathrm{ml}$, four subjects) and monocytes $\left(0.5 \times 10^{6}-6 \times\right.$ $10 \% \mathrm{ml}$, four subjects).

\section{Results}

Neutrophils and monocytes from each patient studied produced detectable chemiluminescence 
Figure 1: Cell concentration and chemiluminescent response. The relationship between the number of $(a)$ neutrophils and (b) monocytes stimulated with phorbol myristate acetate (PMA) and the magnitude of the chemiluminescent response. Each point represents the mean $(S E)$ triplicate measurements.
Figure 2: Chemiluminescent response to chemotactic stimulation. The

chemiluminescent response of neutrophils and monocytes

from controls $(\square)$ and

patients with active Crohn's disease and ulcerative colitis (O), and inactive

inflammatory bowel disease (O), to stimulation with the chemotactic peptide formylmethionyl-leucyl-

phenylalanine ( $F M P$, 1

$\mu M)$. Each point represents the mean of triplicate

measurements. Horizontal

bar represents the median

value for each group of

patients.

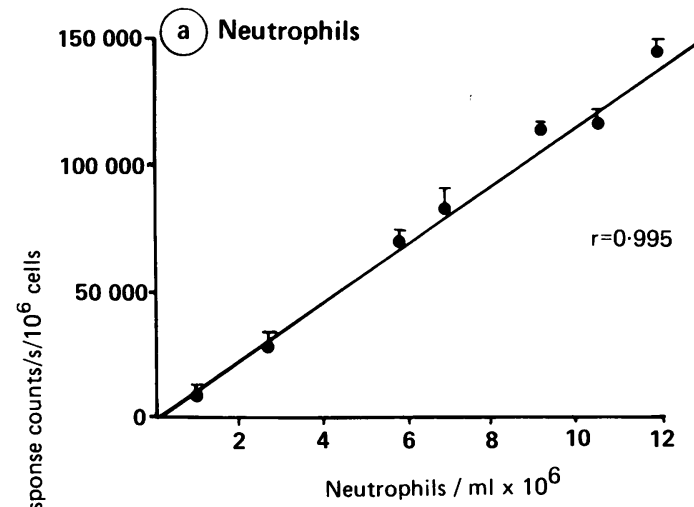

disease cells. There was direct, linear correlation between the magnitude of the peak chemiluminescent response and the number of neutrophils per millilitre in the four samples of neutrophils, $r=0.995,0.995,0.996$ and 0.907 (Fig la). Similarly, there was also direct, linear correlation between the number of monocytes and the magnitude of their chemiluminescent response in the four samples of mononuclear cells, $r=0.98,0.998,0.978$ and 0.985 (Fig lb).

\section{CHEMILUMINESCENT RESPONSE TO}

CHEMOTACTIC STIMULATION

The magnitude of the median chemiluminescent response of both neutrophils and monocytes from each subject to chemotactic stimulation with fMLP is shown in Figure 2.

The median response of neutrophils from control subjects was 551 counts per second per $10^{6}$ neutrophils (cps). The response of neutrophils from patients with Crohn's disease to fMLP was significantly lower, median 312 $(p=0 \cdot 018)$, as was the response of neutrophils from patients with ulcerative colitis, median 265 $(\mathrm{p}=0 \cdot 043)$.

In contrast, the chemiluminescent response of monocytes from patients with Crohn's disease

after each stimulus. There was no difference in was significantly greater than those of controls the pattern of chemiluminescent response (control median response $72 \mathrm{cps}$, Crohn's disease between controls and inflammatory bowel $313 \mathrm{cps}, \mathrm{p}<0.002)$. There was no significant

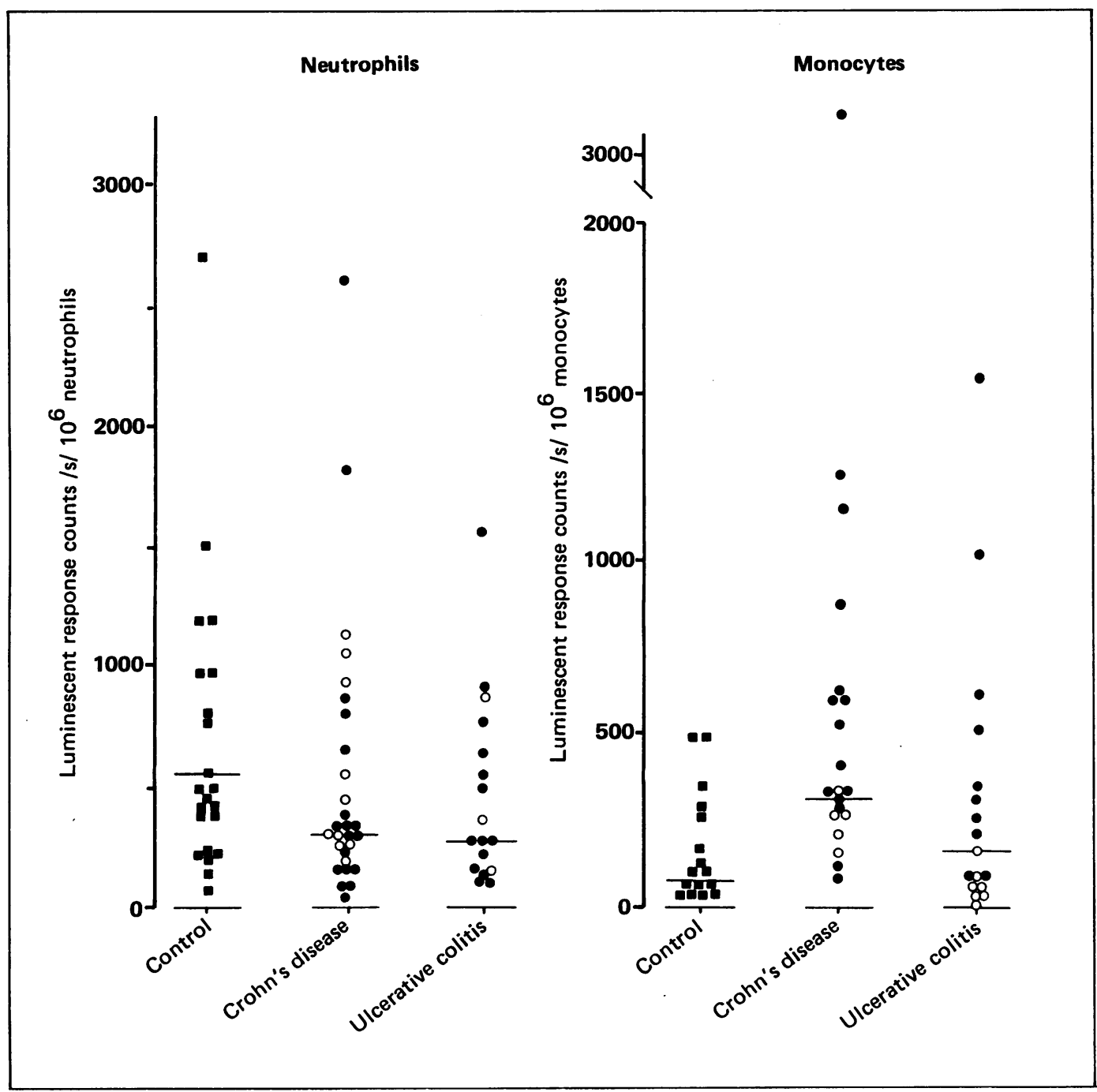


Figure 3: Chemiluminescent response to phagocytic stimulation with latex beads 0.7 um diameter, $10^{2} /$ cell. See legend Figure 2 for details and text for significance values.

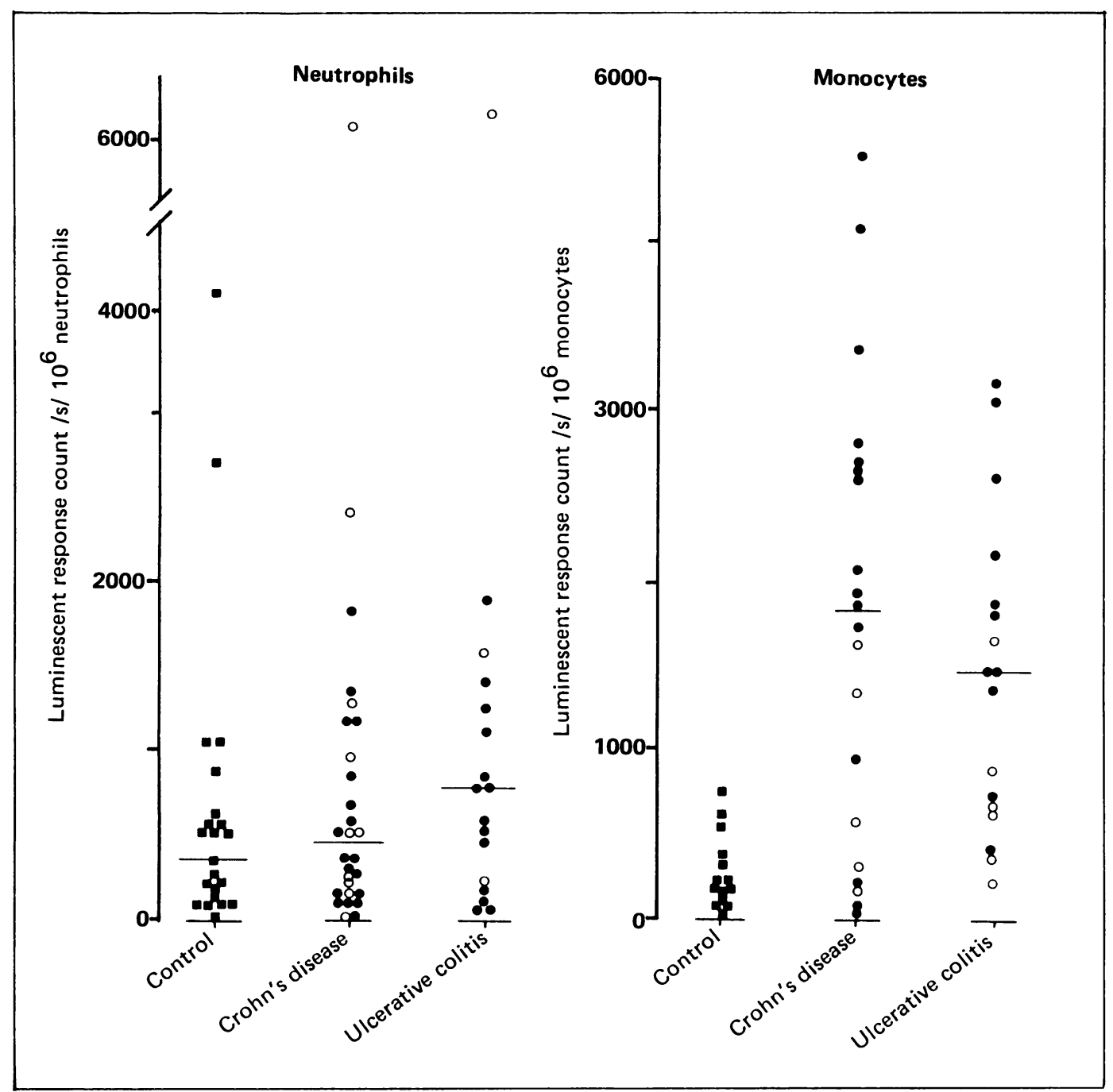

difference between the response of monocytes from patients with ulcerative colitis (median 159 cps) and controls.

\section{CHEMILUMINESCENT RESPONSE TO \\ PHAGOCYTIC STIMULATION}

The median chemiluminescent response of both neutrophils and monocytes from each subject to phagocytic stimulation with latex beads is shown in Figure 3. There was no significant difference between the chemiluminescent response of neutrophils from controls and patients with inflammatory bowel disease (median responses; control, 366 cps; Crohn's disease 452 cps and ulcerative colitis $681 \mathrm{cps}$.

The chemiluminescent response of monocytes, however, was significantly greater for patients with inflammatory bowel disease compared to controls. Control median response 230 cps, Crohn's disease $1803(\mathrm{p}<0.002)$, ulcerative colitis $1460(\mathrm{p}<0.0005)$.

\section{CHEMILUMINESCENT RESPONSE TO} PHORBAL MYRISTATE ACETATE

The responses of neutrophils and monocytes to phorbol myristate acetate are shown in Figure 3. There was no significant differences between the responses of neutrophils from controls and patients with inflammatory bowel disease (median responses; controls, $7014 \mathrm{cps;} \mathrm{Crohn's}$ disease $6194 \mathrm{cps}$ and ulcerative colitis $8234 \mathrm{cps}$ ).

The response of monocytes from patients with inflammatory bowel disease was significantly greater than control responses. Control median $280 \mathrm{cps}$, Crohn's disease $1883 \mathrm{cps}(\mathrm{p} 0<0 \cdot 0005)$, ulcerative colitis $1060 \mathrm{cps}(\mathrm{p}<0 \cdot 05)$.

\section{EFFECT OF DISEASE ACTIVITY ON}

\section{CHEMILUMINESCENT RESPONSE}

There was no difference in the response of neutrophils from patients with inactive disease compared to the response of neutrophils from patients with active disease for any of the three stimuli used (Figs 2-4). Similarly, drug therapy did not appear to influence the magnitude of the chemiluminescent response of neutrophils or monocytes.

The chemiluminescent response of monocytes from patients with active Crohn's disease however was significantly greater than the response of patients with inactive disease after stimulation with fMLP (inactive median response $207 \mathrm{cps,}$ active $526 \mathrm{cps}, \mathrm{p}<0.02)$ and after stimulation with phorbol myristate acetate (inactive $535 \mathrm{cps}$, active 2419 cps, $p<0.05)$. The difference in response after stimulation with latex beads was not statisically significant (inactive $591 \mathrm{cps}$, active $1942 \mathrm{cps}$ ). For each stimulus there was no significant difference in the magnitude of the 
Figure 4: Chemiluminescent response to stimulation with phorbol myristate acetate

$(P M A, 1 \mu \mathrm{g} / \mathrm{ml})$. See legend Figure 2 for details and text for significance values.

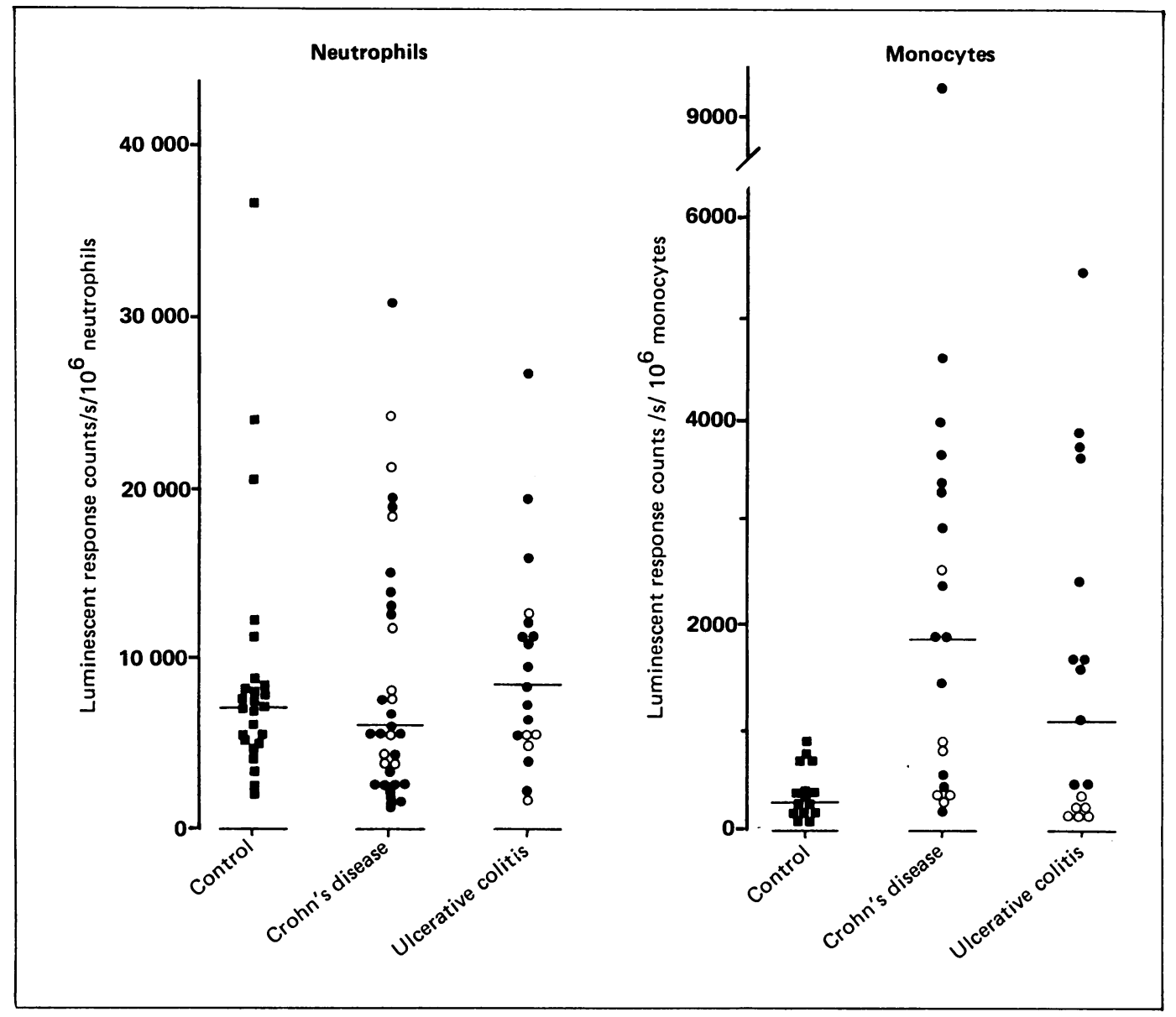

response of monocytes from patients with inactive Crohn's disease and control subjects.

A similar relationship was seen in ulcerative colitis, with significantly greater activity by monocytes from patients with active disease compared to patients with inactive ulcerative colitis. After stimulation with phorbol myristate acetate, the response of monocytes from patients with inactive disease was 174 cps and from patients with active disease $1655 \mathrm{cps}$ $(\mathrm{p}<0.0002)$; after fMLP, 58 cps and $305 \mathrm{cps}$ respectively $(p<0.01)$ and after latex beads 655 cps and 1881 cps respectively $(p=0 \cdot 02)$. The response of monocytes from patients with in active ulcerative colitis was not significantly different from the response of control monocytes.

EFFECT OF TREATMENT WITH STEROIDS The effect of treatment of the patient with

TABLE I Effect of treatment with steroids on the chemiluminescent response of phagocytic cells from patients with active inflammatory bowel disease

\begin{tabular}{|c|c|c|c|c|}
\hline \multirow{2}{*}{$\frac{\text { Crohn's disease }}{\text { Steroid treatment }}$} & \multicolumn{2}{|l|}{ Neutrophils } & \multicolumn{2}{|l|}{ Monocytes } \\
\hline & Yes & No & Yes & No \\
\hline Patients(n) & 15 & 7 & 10 & 5 \\
\hline Phorbal myristate acetate & 5857 & 5577 & 1687 & 3330 \\
\hline fMLP & 325 & 258 & 467 & 592 \\
\hline Beads & 375 & 258 & 1837 & 2717 \\
\hline Ulcerative colitis & Neutrophils & & Monocytes & \\
\hline Steroid treatment & Yes & No & Yes & No \\
\hline Patients(n) & 11 & 3 & 8 & \\
\hline Phorbol myristate acetate & 5442 & 8613 & 2658 & 1027 \\
\hline fMLP & 263 & 489 & 327 & 802 \\
\hline Beads & 1143 & 394 & 1649 & 2691 \\
\hline
\end{tabular}

Median chemiluminescent response expressed as counts per second per $10^{6}$ cells. steroids, on the chemiluminescent response of neutrophils and monocytes, was investigated in patients with active Crohn's disease and active ulcerative colitis. The results are shown in the Table. There was no significant difference in the magnitude of the chemiluminescent response of either neutrophils or monocytes in Crohn's disease or ulcerative colitis for any of the three stimuli. The number of patients not being treated with steroids was, however, small.

\section{Discussion}

In this paper, we have shown that circulating neutrophils and monocytes from patients with inflammatory bowel disease generate toxic metabolites of oxygen, measured by luminol dependent chemiluminescence, in response to three different stimuli. Toxic oxygen metabolite production by phagocytic cells after stimulation with FMLP is dependent on a transient rise in intracellular calcium. ${ }^{16}$ Latex beads, and other phagocytic stimuli, activate phagocytes by a mechanism independent of changes in intracellular calcium, but which involve the enzyme C-kinase. ${ }^{1617}$ Phorbol myristate acetate is a potent stimulus of toxic oxygen metabolite production by phagocytes and activates C-kinase directly. Thus it appears that activation of toxic oxygen metabolite production by phagocytic cells occurs via at least two different intracellular pathways.

There was no difference in the response of neutrophils from patients with inflammatory bowel disease and controls after stimulation with 
latex beads or phorbol myristate acetate. The response to fMLP was slightly depressed in both Crohn's disease and ulcerative colitis. Although this was statistically significant, there was considerable overlap between the three groups. Thus, it would appear that a generalised defect of toxic oxygen metabolite production by neutrophils is not present in either Crohn's disease or ulcerative colitis. Depressed chemotaxis of neutrophils in vitro in inflammatory bowel disease has been previously reported ${ }^{18: 2}$ and depressed toxic oxygen metabolite production therefore may be secondary to a defective neutrophil response to chemotactic stimulation.

Increased chemiluminescence in response to zymosan has been reported ${ }^{23}$ although the numbers studied were small and included patients with both Crohn's disease and ulcerative colitis as one group. Other studies, however, have reported no difference in the levels of luminol dependent chemiluminescence between controls and patients with Crohn's disease after stimulation with opsonised zymosan ${ }^{24}$ and phorbol myristate acetate. ${ }^{25}$

Diminished production of hydrogen peroxide by neutrophils from patients with untreated Crohn's disease has been reported, ${ }^{26}$ with normal production of hydrogen peroxide by neutrophils from patients with ulcerative colitis and Crohn's disease on medical treatment. ${ }^{27} 27$ Superoxide production has also been reported to be significantly depressed in ulcerative colitis ${ }^{2728}$ and Crohn's disease ${ }^{28}$ in some studies, whereas in others the depression of superoxide production by neutrophils in Crohn's disease was only slight. ${ }^{26} 27$

Interpreting these findings is difficult. As hydrogen peroxide is produced by reduction of superoxide, ${ }^{3}$ a marked diminution in superoxide production would be expected to be associated with similar depression of hydrogen peroxide production.

In vivo, neutrophil activation results in the production of a series of interrelated toxic metabolites of oxygen, coupled with the release of granular enzymes ${ }^{29}$ and formation of highly reactive metabolites such as hypochlorite. ${ }^{5}$ The generation of luminol dependent chemiluminescence by phagocytic cells requires both the production of oxygen metabolites and enzyme release and probably reflects hypochlorite ion generation. ${ }^{3031}$ This method of measuring toxic oxygen metabolite production in vitro, therefore, more accurately reflects events in vivo.

Toxic oxygen metabolite production by circulating monocytes has received less attention in inflammatory bowel disease than neutrophils. This is surprising in view of the relationship between monocytes and tissue macrophages. In this study, we have shown that toxic oxygen metabolite production by circulating monocytes is significantly greater in both Crohn's disease and ulcerative colitis compared with normal controls. Furthermore, this enhanced production of oxygen metabolites was confined to monocytes from patients with active inflammatory bowel disease. Increased chemiluminescence was seen in response to each of the three different stimuli used, suggesting a generalised increased oxidative potential of these cells. Two other studies have shown increased luminol dependent chemiluminescence by circulating monocytes in Crohn's disease ${ }^{2+24}$ but in neither study was a relationship to disease activity shown.

In mice, activation of the mononuclear phagocyte system by $C$ parvum, vaccinia or murine cytomegalo virus was associated with enhanced chemiluminescence by stimulated peritoneal macrophages. ${ }^{32}$ Similarly, increased superoxide and hydrogen peroxide production by macrophages activated in vivo and in vitro has been reported. ${ }^{33.35}$

The results presented here suggest that circulating monocytes in patients with inflammatory bowel disease are 'activated'. This is supported by studies relating to other monocyte functions in inflammatory bowel disease including; - increased phagocytosis of $C$ albicans and $S$ aureas, ${ }^{36,-38}$ increased lysosomal hydrolase content,$^{39+1}$ increased enzyme release, ${ }^{39+11}$ increased random motility and chemotaxis ${ }^{42}$ and increased IgG and C3b receptor activity. ${ }^{+3}$ Similar 'activation' of circulating monocytes has been shown in other chronic inflammatory conditions such as rheumatoid arthritis." Therefore a generalised defect in toxic oxygen metabolite production by phagocytic cells is unlikely to be involved in the aetiology of inflammatory bowel disease. The response of the two types of circulating phagocytes studied, however, differed in inflammatory bowel disease. Neutrophils appeared to be functioning normally, whereas monocytes produced an enhanced response when stimulated. It is of interest that pulmonary mononuclear phagocytic cells also have enhanced oxidative metabolism. ${ }^{+1}$ Further study is required to define the precise role of phagocytic cells in the aetiology of inflammatory bowel disease, especially of phagocytes at the site of inflammation in the bowel wall.

JGW was supported by a Wellcome Research Training Fellowship in Surgery.

1 Morson BC, Dawson IMP Gastrointestinal pathologv. Oxford. Blackwell Scientific Publications, 1979.

2 Metchnikoff $\mathrm{E}$. Immunity in infective diseases. Cambridge. Cambridge University Press, 1905.

3 Babior BM. Oxygen-dependent microbial killing by phagocytes. New Engl F Med 1978; 298: 659-68.

4 Klebanoff SJ. Oxygen metabolism and the toxic properties of phagocytes. Ann Intern Med 1980; 93: 480-9.

5 Weiss SJ. Oxygen, ischaemia and inflammation. Acta Phvsiol Scand 1986; (Suppl 548): 9-37.

6 Thompson H. Histopathology of Crohn's disease. In: Allen RN, Keighley MRB, Alexander Williams J, Hawkins C, eds. Inflammatory bowel diseases. Edinburgh: Churchill Livingstone, $198 \tilde{3} ; 392-411$

7 Ament ME, Ochs HD. Gastrointestinal manifestations of chronic granulomatous disease. New Engl f Med 1973; 288: $382-7$.

8 Curnutte JT, Whitten DM, Babior BM. Defective superoxide production by granulocytes from patients with chronic production by granulocytes from patients with : 593-7.

9 Ward M. The pathogenesis of Crohn's disease. Lancet 1977; ii: 903-5.

10 DeDombal FT, Burton IL, Clamp SE, Goligher JC. Short term course and prognosis of Crohn's disease. Gut 1974; 15: 435-43.

11 Truelove SC, Witts LJ. Cortisone in ulcerative colitis: Fina report on a therapeutic trial. $\mathrm{BrMed} \mathcal{F} 1955$; ii: $1041-8$.

12 Skoog WA, Beck WS. Studies on fibrinogen, dextran and phytohaemagglutinin methods of isolating leukocytes. Blood 1956; 11: 436-54.

13 Yam LT, Li CY, Crosby WH. Cytochemical identification of monocytes and granulocytes. Am $\mathcal{F}$ Clin Pathol 1971; 55: 283-90.

14 Allen RC, Loose L.D. Phagocytic activation of a luminoldependent chemiluminescence in rabbit alveolar and peritoneal macrophages. Biochem Biophys Res Commun 1976;69. 245-52. 
15 Campbell AK, Hallett MB, Weeks I. Chemiluminescence as an analytical tool in cell biology and medicine. Methods an analytical tool in cell biology
Biochem Anal 1985; 31: 317-415.

16 Hallett MB, Campbell AK. Two distinct mechanisms for stimulation of oxygen-radical production by polymorphonuclear leucocytes. Biochem f 1983; 216: 459 65.

17 Cooke E, Hallett MB. The role of C-kinase in the physiological activation of the neutrophil oxidase. Biochem $\mathcal{F} 1985 ; 232$ : 323-7.

18 Binder V, Riis P. The leukocyte chemotactic function in patients with ulcerative colitis. Scand $\mathcal{F}$ Gastoenterol 1977; 12: $141-4$.

19 Belsheim J, Gnarpe H, Persson S. Granulocyte chemotaxis in Crohn's disease. Acta Chir Scand 1981; 147: 197-200.

20 Hermanowicz A, Nawarska Z. Chemotaxis and random migration of polymorphonuclear leukocytes in ulcerative colitis examined by the agarose method. Scand $\mathcal{f}$ Gastroenterol examined by the

21 Elmgreen J, Binder V. The chemotactic function of neutrophils in ulcerative colitis. Scand $\mathcal{F}$ Gastroenterol 1982; 17: $561-4$

22 Kirk AP, Cason J, Fordham KA, et al. Polymorphonuclear leukocyte function in ulcerative colitis and Crohn's disease. Dig Dis Sci 1983; 28: 236-48.

23 Faden H, Rossi TM. Chemiluminescent response of neutrophils form patients with inflammatory bowel disease. Dig Dis Sci 1985; 30: 139-42.

24 Okabe N, Kuroiwa A, Fujita K, et al. Immunological studies on Crohn's disease. VI. Increased chemiluminescent response of peripheral blood monocytes. F Clin Lab Immunol ponse of periph
1986; $21: 11-5$.

25 Kitahora T, Suzuki K, Asakura H, et al. Active oxygen species generated by monocytes and polymorphonuclear cells in geros and polymorphon

26 Verspaget HW, Mieremet-ooms MAC, Weterman IT, et al. Partial defect of neutrophil oxidative metabolism in Crohn's disease. Gut 1984; 25: 849-53.

27 Verspaget HW, Elmgreen J, Weterman IT, et al. Impaired activation of the neutrophil oxidative metabolism in chronic inflammatory bowel disease. Scand $\mathcal{F}$ Gastroenterol 1986; 21 : 1124-30.

28 Verspaget HW, Pena AS, Weterman IT, Lamers CBHW. Diminished neutrophil function in Crohn's disease and ulcerative colitis identified by decreased oxidative metabolism and low superoxide dismutase content. Gut 1988; 29: 223-8.

29 Fantone JC, Ward PA. Role of oxygen-derived free radicals and metabolites in leukocyte-dependent inflammatory reacand metabolites in leukocyte-dependen
tions. Am F Pathol 1982; 107: 397-418.
30 DeChatelet LR, Long GD, Shirley PS, et al. Mechanism of the liminol-dependent GD, Shirley PS, et al. Mechanism of the liminol-dependent chemiluminescen

31 Dahlgren C, Stendahl O. Role of myeloperoxidase in luminoldependent chemiluminescence of polymorphonuclear leukocytes. Infect Immun 1983; 39: 736-41

32 Schleupner CJ, Glascow LA. Peritoneal macrophage activation indicated by enhanced chemiluminescence. Infect Immun 1978; 21 : 886-95.

33 Johnston RB, Godzick CA, Cohn Z. Increased superoxide anion production by immunologically activated and chemically elicited macrophages. $\mathcal{E}$ Exp Med 1978; 148: 115-27.

34 Nathan C Nogueira N, Juangbhanich C, et al Activation of macrophages in vivo and in vitro. Correlation between hydrogen peroxide rele and killing of Trypanosoma cruai. fExp Med 1979; 149: 1056-68.

35 Murray HW, Cohn ZA. Macrophage oxygen-dependent antimicrobial activity. iii enhanced oxidative metabolism as an microbial activity. iii enhanced oxidative metabolism as an expression

36 Mee AS, Szawatakowski M, Jewell DP Monocytes in inflammatory bowel disease: phagocytosis and intracellular killing. f Clin Pathol 1980; 33: 921-5.

37 Jewell DP, Mee AS, Rhodes JM. Monocyte function in Crohn's disease. In: Pena AS, Weterman IT, Booth CC, Strober $\mathrm{W}$, eds. Recent advances in Crohn's disease. The Hague: Martinus Nijhoff, 1981: 424-30.

38 Whorwell PJ, Bennett P, Tanner AR, Wright R. Monocyte function in Crohn's disease and ulcerative colitis. Digestion 1981; 22: 271-5.

39 Ganguly NK, Lloyd B, Price CP, et al. Acid hydrolases in monocytes from patients with inflammatory bowel disease,
chronic liver disease, and rheumatoid arthritis. Lancet 1978; i: $1073-5$.

40 Doe WF, Temple C, Dorsman B, Golder J. Activation of mononuclear phagocytes in chronic inflammatory bowel
disease. [Abstract.] Gastroenterology 1980;78: A1158.

41 Mee AS, Jewell DP. Monocytes inflammatory bowel disease: monocyte and serum lysosomal enzyme activity. Clin $\mathrm{Sc}$ 1980; 58: 295-300.

42 Rhodes JM, Jewell DP. Motility of neutrophils and monocytes in Crohn's disease and ulcerative colitis. Gut 1983; 24: 73-7.

43 Schmidt ME, Douglas SD. Monocyte IgG receptor activity, dynamics and modulation-normal individuals and patients with granulomatous disease. I Lab Clin Med 1977; 89: with gram

44 Bonniere $\mathrm{P}$, Wallaert $\mathrm{B}$, Cortot A, et al. Latent pulmonary involvement in Crohn's disease: biological, functional, bronchoalveolar lavage and scintigraphic studies. Gut 1986; 27: $919-25$. 